\title{
O PORTAL DA TRANSPARÊNCIA COMO FERRAMENTA DE ACOMPANHAMENTO DAS BOLSAS ESTUDANTIS
}

\section{ARTIGO ORIGINAL}

BARROS, Thiago Tavares de ${ }^{1}$

SOUZA, Cristina Gomes de ${ }^{2}$

BARROS, Thiago Tavares de. SOUZA, Cristina Gomes de. O portal da transparência como ferramenta de acompanhamento das bolsas estudantis. Revista Científica Multidisciplinar Núcleo do Conhecimento. Ano 06, Ed. 01, Vol. 05, pp. 45-62. Janeiro de 2021. ISSN: 2448-0959, Link de acesso: https://www.nucleodoconhecimento.com.br/engenharia-de-producao/bolsasestudantis

\section{RESUMO}

O Portal da Transparência permite a todo cidadão ter acesso a informações relacionadas à gestão pública, incluindo benefícios pagos pelo governo federal. Dentre esses benefícios encontram-se as diversas modalidades de bolsas relacionadas ao ensino, pesquisa e extensão. Este trabalho tem por objetivo contribuir para divulgação e utilização do Portal de Transparência por parte dos alunos bolsistas de uma Instituição Federal de Ensino Superior. No âmbito do trabalho buscou-se identificar: o conhecimento e utilização do Portal da Transparência por parte dos alunos; e sua percepção quanto à linguagem, facilidade de navegação e publicidade dessa ferramenta de acesso livre. $\mathrm{O}$ estudo foi baseado em pesquisa bibliográfica e documental para fundamentação teórica e obtenção de dados relacionados ao Portal da Transparência e às bolsas concedidas; levantamento das dúvidas dos alunos através do sistema de chamados da instituição; e aplicação de questionários para os

\footnotetext{
${ }^{1}$ Pós-graduado em Gestão Pública, Graduado em Ciências Contábeis.

2 Orientadora. Doutorado em Engenharia de Produção.
} 
alunos bolsistas. Dentre outros resultados, o estudo mostrou que os alunos bolsistas consideram o Portal da Transparência pouco divulgado e que a ferramenta possuí termos técnicos de difícil compreensão, além de não ser de fácil navegação. $\mathrm{A}$ contribuição desse estudo consiste em apontar implicações práticas à disseminação do uso do Portal da Transparência, de modo a permitir: mitigar o risco de erros e falhas que possam vir a prejudicar o processo de concessão de bolsas; reduzir o tempo gasto com o atendimento dos alunos e o retrabalho dos servidores que atuam nos setores responsáveis pela implementação e concessão dessas bolsas; e agilizar a obtenção das informações por parte dos alunos. Ressalta-se que levantamentos preliminares não apontaram existência de artigos voltados para a utilização do Portal da Transparência como mecanismo de acompanhamento de bolsas de alunos. Assim sendo, o presente estudo busca reduzir esse gap da literatura.

Palavras-chave: Portal da Transparência, assistência estudantil, Bolsista, IES.

\section{INTRODUÇÃO}

Os alunos das instituições educacionais que, por direito, recebem bolsa estudantil, utilizam-se desse recurso para auxiliar na produção de seus trabalhos e continuidade dos estudos, sendo de grande importância o acompanhamento do recebimento desse auxílio financeiro. Este projeto objetiva viabilizar e apoiar a educação nos diferentes níveis de ensino, abrangendo desde o ensino fundamental até a pós-graduação. Segundo Watakabe (2015), as bolsas ofertadas ajudam na manutenção econômica de alunos de baixa renda visando reduzir a evasão escolar.

O Portal da Transparência, por sua vez, é uma ferramenta pública de acesso livre, que aproxima a população do governo e que tem como propósito principal a questão do controle social por meio do acompanhamento dos gastos dos recursos públicos (PORTAL DA TRANSPARÊNCIA, 2014).

Dentre as diversas funções que existem no ambiente virtual do portal, pode ser citada a disponibilização de informações relativas ao pagamento de bolsas estudantis, onde os beneficiários podem acompanhar todo o processo que envolve o recebimento do 
seu recurso, processo esse que passa pelas fases do empenho, liquidação até chegar ao pagamento.

O processo entre a concessão e o recebimento da bolsa estudantil, abrange várias etapas complementadas por um conjunto de documentos e informações. É comum ocorrer erros nesse processo, de modo a impedir ou atrasar o pagamento dos benefícios.

Desta forma, verifica-se a importância de um monitoramento sobre essas etapas, objetivando a redução dos erros frequentes que, geralmente, ocorrem na numeração de dados bancários e de CPFs no pagamento das bolsas. Tendo identificado esses erros antes do processo de pagamento, o bolsista pode solicitar a correção dos dados, a fim de se evitar o atrase do pagamento da sua bolsa e o comprometimento da sua programação financeira.

Acrescenta-se que, ao consultar o processamento e pagamento do seu benefício através do Portal da Transparência, os bolsistas passam a ter respostas mais rápidas para os seus questionamentos, sem depender de entrar em contato e aguardar o retorno dos funcionários responsáveis.

Por sua vez, sob a perspectiva institucional, o acompanhamento do processo pelos alunos contribui para a identificação antecipada de possíveis erros, de modo a evitar o retrabalho dos servidores responsáveis para refazer os documentos e viabilizar o pagamento das bolsas. Ademais, observa-se que esses servidores estão constantemente sendo solicitados para fornecerem esclarecimentos e informações relacionadas à concessão desses benefícios, podendo, desta forma, esse tempo gasto no atendimento a essa demanda ser utilizado para a execução de outras atividades.

Outro aspecto a ser ressaltado é que o acompanhamento dos benefícios através do Portal da Transparência contribui para estimular sua utilização, divulgar suas funcionalidades e incentivar o acompanhamento dos gastos públicos por parte dos estudantes e da sociedade. 
Diante do contexto apresentado, este trabalho tem por objetivo geral estimular e contribuir para a utilização do Portal da Transparência como mecanismo de acompanhamento da concessão e pagamento das bolsas estudantis por parte dos beneficiários de uma Instituição Federal de Ensino Superior (IFES). Especificamente buscou-se identificar: No âmbito do trabalho buscou-se identificar: o conhecimento e utilização do Portal da Transparência por parte dos alunos; e sua percepção quanto à linguagem, facilidade de navegação e publicidade dessa ferramenta de acesso livre.

A IFES objeto do estudo oferece diversos cursos de ensino técnico de nível médio, graduação, especialização, mestrado e doutorado. A instituição possui oito campi distribuídos em sete municípios do Estado do Rio de Janeiro e contempla doze modalidades de bolsas com diferentes finalidades. O estudo abrangeu todos os campi e teve como foco os alunos - do técnico de nível médio e da graduação - beneficiários das modalidades de bolsas de assistência estudantil (PAE, PAEM, PAED) e monitoria. O estudo foi desenvolvido considerando dados a partir de 2015.

Esse artigo encontra-se dividido em seis seções. Além da presente introdução, as demais seções abordam a revisão da literatura sobre o Portal da Transparência, uma breve descrição das modalidades de bolsas contempladas no estudo, a metodologia utilizada e os resultados obtidos seguidos das considerações finais.

\section{O PORTAL DA TRANSPARÊNCIA}

A transparência nos dados públicos é um tema que tem sido discutido há tempos por diversos países ao redor do mundo. Conforme Grimmelikhuijsen et al. (2013), a transparência é considerada democrática por sustentar uma relação de confiança, alto desempenho e visibilidade das ações de um governo responsável com a administração pública perante a população. Ainda segundo os autores, a transparência governamental deve ser constituída por três dimensões: transparência da tomada de decisões; transparência da informação política; e transparência do resultado da política. 
No Brasil a transparência pública se tornou notória a partir da promulgação da Lei Complementar $n \cong$ 101/2000 que trata da responsabilidade fiscal (INTEGRADA et al., 2014). No país existem diversas legislações que tratam do processo de transparência das informações públicas, assim como da sua proteção em se tratando de informações sigilosas (FUMEC et al., 2011). No entanto, cabe destacar a Lei de Acesso à Informação (Lei no 12.527, de 18 de novembro de 2011) que regulamentou o direito constitucional de acesso à informação pública, definindo que é dever da administração pública, mesmo que sem solicitação, divulgar em plataformas de fácil acesso, as informações que forem de interesse da sociedade (BRASIL, 2011).

O Portal da Transparência foi desenvolvido dentro desse contexto com o propósito de permitir que a população acompanhe a utilização dos recursos públicos, bem como, de facilitar a participação da sociedade em discussões relativas às políticas públicas permitindo o controle social (PORTAL DA TRANSPARÊNCIA, 2014).

De acordo com Ricardo e Abdala (2016), o Portal da Transparência é a ferramenta usada como recurso para obtenção de dados públicos com acesso à informação detalhada, caracterizando-se como um espaço democrático de modo a fortalecer a participação e controle da população. Os autores, entretanto, alertam para as dificuldades de navegação pelo referido portal uma vez que o mesmo não oferece recurso simplificado, o que é essencial para a sua utilização por parte da sociedade.

$\mathrm{Na}$ literatura são encontrados diversos estudos abordando a transparência pública. Os quadros 1 e 2 relacionam potenciais aspectos positivos e benefícios, bem como, potenciais problemas, fragilidades e óbices que podem ser associados ao Portal da Transparência.

Quadro 1. Potenciais aspectos positivos e benefícios do Portal da Transparência.

\begin{tabular}{|l|l|l|}
\hline Aspectos positivos/benefícios & Referência & Fonte \\
\hline $\begin{array}{l}\text { Sociedade instruída e informada por meio de } \\
\text { programas do governo }\end{array}$ & $\begin{array}{l}\text { Gama; Rodrigues } \\
\text { (2016) }\end{array}$ & Scielo \\
\hline
\end{tabular}




\begin{tabular}{|c|c|c|}
\hline $\begin{array}{l}\text { Promover a interação do governo com } 0 \\
\text { cidadão }\end{array}$ & Brasil (2014) & Governo \\
\hline $\begin{array}{l}\text { Ganho no desempenho de fornecimento de } \\
\text { informação }\end{array}$ & $\begin{array}{l}\text { Santos; } \quad \text { Denner } \\
(2017)\end{array}$ & Scielo \\
\hline Redução da corrupção & $\begin{array}{l}\text { Caldas; Costa; } \\
\text { Pagliarussi (2016) }\end{array}$ & Scielo \\
\hline $\begin{array}{l}\text { Aumento na qualidade dos serviços, sua } \\
\text { eficiência e eficácia }\end{array}$ & $\begin{array}{l}\text { Brusca; Martínez } \\
(2016)\end{array}$ & $\begin{array}{l}\text { Web of } \\
\text { Science }\end{array}$ \\
\hline $\begin{array}{l}\text { Entendimento da população sobre as rotinas } \\
\text { públicas }\end{array}$ & Valle-Cruz (2019) & $\begin{array}{l}\text { Web of } \\
\text { Science }\end{array}$ \\
\hline Maior confiança na administração pública & $\begin{array}{l}\text { Jensen; } \\
\text { Meisenbach (2015) }\end{array}$ & $\begin{array}{l}\text { Web of } \\
\text { Science }\end{array}$ \\
\hline Democratização das informações & Ingrams (2017) & $\begin{array}{l}\text { Web of } \\
\text { Science }\end{array}$ \\
\hline $\begin{array}{l}\text { Disponibilidade e disseminação de } \\
\text { informações sobre a economia }\end{array}$ & $\begin{array}{l}\text { Shambaugh; Shen } \\
(2018)\end{array}$ & $\begin{array}{l}\text { Web of } \\
\text { Science }\end{array}$ \\
\hline Integração de informações & $\begin{array}{l}\text { Ramírez; Tejada } \\
(2019)\end{array}$ & $\begin{array}{l}\text { Web of } \\
\text { Science }\end{array}$ \\
\hline $\begin{array}{l}\text { Competitividade ao gerar um processo } \\
\text { eficiente, conseguindo a redução de custos e } \\
\text { tempo para a cidadania }\end{array}$ & Valle-Cruz (2019) & $\begin{array}{l}\text { Web of } \\
\text { Science }\end{array}$ \\
\hline el em tempo integral & $\begin{array}{l}\text { Portal da } \\
\text { Transparência } \\
(2014)\end{array}$ & Governo \\
\hline $\begin{array}{l}\text { Maior amplitude de informações entre } \\
\text { governo e população }\end{array}$ & Hale (2013) & $\begin{array}{l}\text { Web of } \\
\text { Science }\end{array}$ \\
\hline $\begin{array}{l}\text { Impacto positivo na qualidade de vida da } \\
\text { população }\end{array}$ & Gant (2008) & Scopus \\
\hline $\begin{array}{l}\text { Facilidade em desenvolver parcerias } \\
\text { externas }\end{array}$ & $\begin{array}{l}\text { Shumate; O'connor } \\
(2010)\end{array}$ & Scielo \\
\hline
\end{tabular}


Fonte: Elaborado pelo próprio autor (2020).

Quadro 2. Potenciais problemas, fragilidades e óbices do Portal da Transparência.

\begin{tabular}{|c|c|c|}
\hline Problemas, fragilidades e Óbices & Referência & Base \\
\hline $\begin{array}{l}\text { Ausência de informações cruciais e demora } \\
\text { nas respostas }\end{array}$ & $\begin{array}{l}\text { Michener; } \\
\text { Contreras; Niskier } \\
(2018)\end{array}$ & Scielo \\
\hline Usuário desfavorecido digitalmente & $\begin{array}{l}\text { Pethig; Kroenung, } \\
\text { (2019) }\end{array}$ & $\begin{array}{l}\text { Web of } \\
\text { Science }\end{array}$ \\
\hline Dados da transparência são limitados & Johnston (2019) & $\begin{array}{l}\text { Web of } \\
\text { Science }\end{array}$ \\
\hline $\begin{array}{l}\text { Dificuldade de acesso por pessoas que não } \\
\text { possuem acesso à internet }\end{array}$ & Gant (2008) & Scopus \\
\hline Ausência das percepções da tecnologia & $\begin{array}{l}\text { Pethig; Kroenun } \\
\text { (2019) }\end{array}$ & $\begin{array}{l}\text { Web of } \\
\text { Science }\end{array}$ \\
\hline $\begin{array}{l}\text { Falta de políticas e estudos sobre os impactos } \\
\text { que essa ferramenta de acesso às informações } \\
\text { acarreta na população }\end{array}$ & Mnjama (2007) & Scopus \\
\hline $\begin{array}{l}\text { Linguagem com grau moderado de termos } \\
\text { técnicos }\end{array}$ & Ingrams (2017) & $\begin{array}{l}\text { Web of } \\
\text { Science }\end{array}$ \\
\hline Resistência cultural às inovações & Papa (2014) & Jus \\
\hline
\end{tabular}

Fonte: Elaborado pelo próprio autor (2020).

\section{BOLSAS ESTUDANTIS}

De acordo com Ribeiro e Mancebo (2013), é necessário que os governos estabeleçam políticas de apoio e fomento às atividades científicas, tecnológicas e educacionais. Só existe desenvolvimento científico e tecnológico se houver uma população com acesso à educação. Portanto, é necessário que os governos estabeleçam políticas que visem 
dar condições para que os estudantes possam ter acesso, se manter e ter um bom desempenho garantindo sua formação acadêmica. As bolsas estudantis de caráter financeiro servem para cobrir total ou parcialmente os gastos básicos de um aluno visando à realização de um curso (UNIVERSIA, 2020).

Existem diversas modalidades de bolsas. Esse estudo, entretanto, se ateve a alunos beneficiários das bolsas de assistência estudantil (PAE, PAEM, PAED) e bolsas de monitoria.

\subsection{BOLSAS DE ASSISTÊNCIA ESTUDANTIL}

Mendes (2013) diz que um dos principais fatores que contribuem para a evasão escolar no Brasil é a condição socioeconômica que faz com que o aluno tenha uma necessidade de ingressar no mercado de trabalho. Com o intuito de mitigar esse problema, as bolsas de assistência estudantil visam proporcionar condições de acesso e permanência dos alunos nos respectivos cursos de formação acadêmica, com o propósito de reduzir os efeitos da desigualdade social, evitar a evasão escolar e promover a inclusão (BRASIL, 2020).

As bolsas estudantis assistenciais e de extensão estão amparadas pela legislação vigente no país. De acordo com a lei oㅜ 12.155, de 23 de dezembro de 2009, nos artigos 10 e 12, as instituições federais ficam obrigadas a oferecer bolsas estudantis para as modalidades assistenciais e de extensão (BRASIL, 2009). Dentre as bolsas de assistência estudantil encontram-se aquelas concedidas pelos seguintes programas governamentais:

- Programa de Auxílio ao Estudante (PAE): destina-se a estudantes que não dispõem de recursos suficientes para arcar com despesas básicas para frequência e desempenho escolar.

- Programa de Auxílio ao Estudante com Deficiência (PAED): destina-se a favorecer a acessibilidade, permanência e formação de qualidade aos estudantes com deficiência. 
- Programa de Auxílio Emergencial (PAEm): destina-se a minimizar as dificuldades socioeconômicas emergenciais que comprometem a permanência do estudante na instituição.

\subsection{BOLSAS DE MONITORIA}

A monitoria tem como objetivos despertar no aluno, com aproveitamento satisfatório, 0 interesse pela carreira docente e assegurar a cooperação do corpo discente com o corpo docente nas atividades de ensino (BRASIL, 2018). Andrade et al. (2018) dizem que o programa de monitoria acadêmica possibilita o desenvolvimento da autonomia do discente-monitor, com o aumento do senso de responsabilidade e ampliação do vínculo do discente-monitor-docente. Os autores afirmam ainda que o projeto de monitoria cria oportunidade para o desenvolvimento de habilidades intrínsecas, além de possibilitar ao monitor aprofundar os conhecimentos em uma área específica e participar do processo ensino-aprendizado. Landahl (2019) acrescenta que o sistema de monitoria na educação baseia-se no princípio de que um professor, com a ajuda de monitores, poderia ensinar muitos alunos ao mesmo tempo.

A bolsa monitoria está amparada pela Lei 9.394 de 20 de dezembro de 1996 em seu artigo 84 vigente (BRASIL, 1996). No Brasil, existem dois tipos de modalidades de monitores:

- Monitores bolsistas: selecionados através de edital previamente publicado com as regras para concessão, sendo beneficiários da percepção de bolsa.

- Monitores voluntários: Selecionados através de edital previamente publicado, não recebendo o auxílio de uma bolsa.

\section{METODOLOGIA}

Este trabalho, de natureza descritiva, fez uso do método misto. Flick (2006) define o método misto como sendo o que utiliza a forma qualitativa e quantitativa como meio de investigação. Para a realização do estudo foram realizadas pesquisa bibliográficas, 
documentais, levantamento de dados da própria instituição e aplicação de questionários.

A pesquisa bibliográfica teve como foco artigos científicos relacionados à temática tratada em plataformas como, Web of Science, Scopus e Scielo. Os documentos consultados foram leis, decretos, relatórios e programas governamentais relacionados às bolsas estudantis, em especial, as que abrangem os programas de auxílio abordados nesse estudo.

O levantamento de dados institucionais abrangeu informações obtidas a partir do seu sítio eletrônico, bem como, solicitações realizadas pela ferramenta governamental $e$ sic, que consiste em pedidos de dados públicos não disponibilizados em ambientes abertos.

A aplicação do questionário se deu junto aos beneficiários de bolsas de estudo das modalidades PAE, PAEM, PAED e monitoria, abrangendo os alunos de técnico de nível médio e graduação. O questionário foi composto por um conjunto de perguntas fechadas (com respostas 'sim', 'não' e 'não sou capaz de opinar' e respostas envolvendo medidas escalares). O questionário foi elaborado por meio do Formulário Google, ferramenta da empresa Google, e enviado através de e-mail para 998 alunos. Houve um retorno de 390 respondentes, sendo que nem todas as perguntas do questionário foram respondidas por todos os alunos.

\section{RESULTADOS}

A primeira pergunta abordou o tempo em que o aluno era bolsista. $O$ intuito dessa pergunta foi verificar, entre os respondentes, a porcentagem dos alunos beneficiários de bolsas por tempo de permanência nos programas. A figura 1 mostra as respostas dos alunos em relação ao seu tempo na modalidade de bolsista. 
Figura 1 Questão sobre o tempo da modalidade na qualidade de bolsista

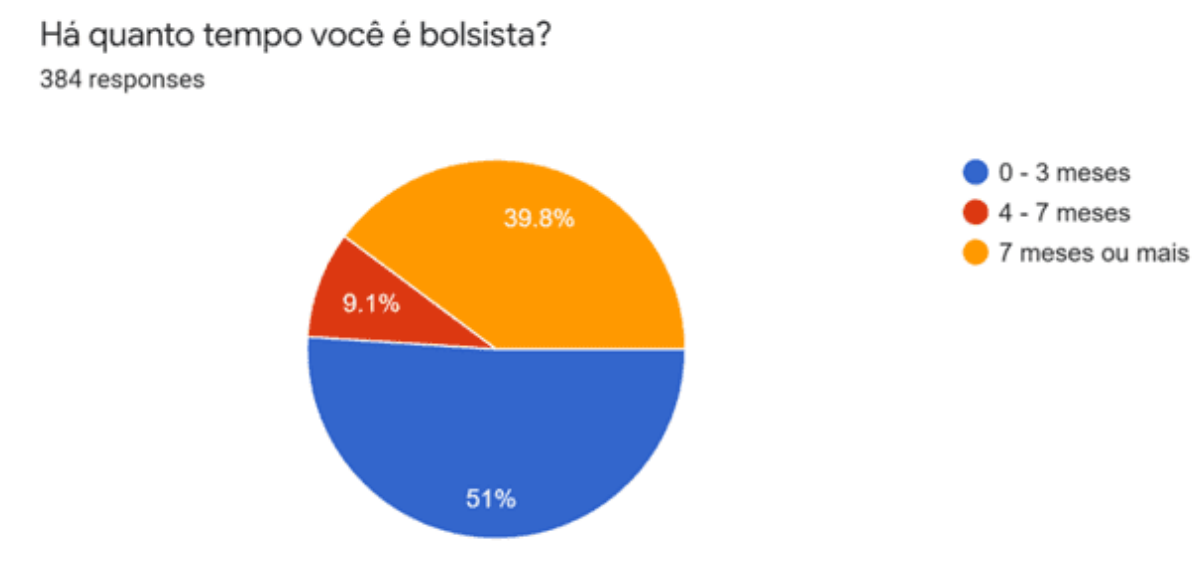

Fonte: Elaborado pelo próprio auto (2020)

De acordo com os dados coletados, $51 \%$ dos respondentes possuem entre 0 e 3 meses no programa de bolsas ofertado pela instituição. Essa porcentagem representa um total de 196 alunos. Por sua vez, 153 alunos, representando 39,8\% dos respondentes, estão no programa de bolsa por 7 meses ou mais. Os alunos entre $4 \mathrm{e}$ 7 meses corresponderam a $9,1 \%$.

O segundo questionamento foi quanto à modalidade de bolsa. Os resultados estão apresentados na figura 2. Conforme pode ser observado, o maior número de respondentes (148 alunos) foram os beneficiários da bolsa assistencial PAE do técnico de nível médio, o que representa $38,2 \%$ do total. Na sequência foram os alunos da mesma modalidade, porém de nível superior, com um total de 102 bolsistas representando $26,4 \%$ dos respondentes.

Os beneficiários de bolsa monitoria, por sua vez, corresponderam a $13,4 \%$ dos respondentes considerando o técnico de nível médio e 12,7\% considerando a graduação, o que equivale a 52 e 49 alunos, respectivamente. 
Figura 2 Questão sobre a modalidade de bolsa dos alunos

Qual é a sua modalidade de bolsa?

387 responses

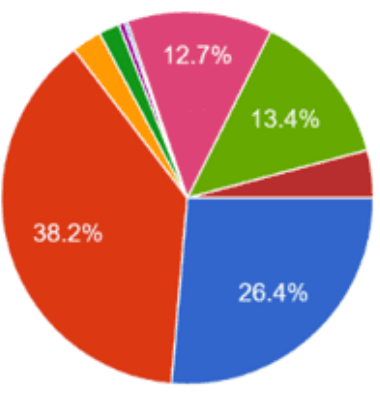

PAE - Programas de Assistência

Estudantil - Graduação

PAE - Programas de Assiste̊ncia Estu...

PAEM - Programa de Assistência eme.

PAEM - Programa de Assistência eme..

- PAED - Programa de Assistência a Po..

- PAED - Programa de Assistência a Po..

Monitoria - Graduação

Monitoria - Ensino Médio

Outro

Fonte: Elaborado pelo próprio auto (2020)

Foram realizadas duas perguntas em relação ao Portal da Transparência no que tange ao conhecimento sobre a ferramenta e a seu acesso. Os dados da figura 3 mostram que $69,1 \%$ dos respondentes já haviam ouvido falar do referido portal e 30,9\% afirmaram nunca ter ouvido falar. Esses percentuais correspondem a 268 e 120 alunos respectivamente.

Figura 3 Respostas dos bolsistas em relação ao conhecimento do Portal da Transparência

O Portal da Transparência è uma das ferramentas do governo eletrônico. Você já ouviu falar nele?

388 responses

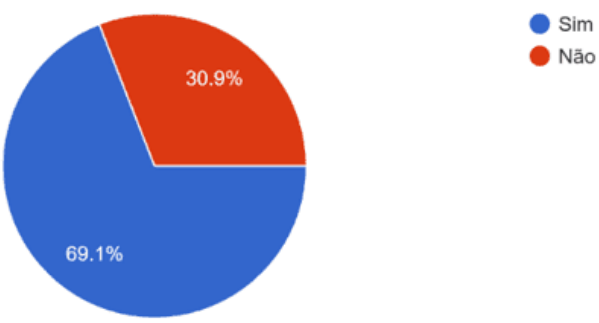

Fonte: Elaborado pelo próprio auto (2020)

RC: 72890

Disponível em: https://www.nucleodoconhecimento.com.br/engenharia-de-producao/bolsasestudantis 
Em relação ao acesso a ferramenta, 50,4\% dos alunos já acessaram o Portal da Transparência, enquanto $49,6 \%$ dos bolsistas nunca acessaram, conforme pode ser visualizado na figura 4 .

Figura 4 Respostas dos bolsistas em relação ao acesso ao Portal da Transparência

Já acessou o Portal da Transparência?

387 responses

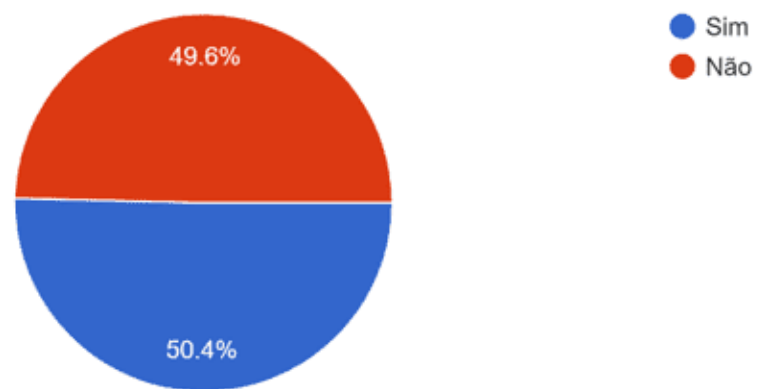

Fonte: Elaborado pelo próprio autor (2020)

Os dados mostraram que, apesar da maioria dos bolsistas já ter ouvido falar no Portal da Transparência, pouco mais de 50\% já o acessaram. A diferença entre o percentual de conhecimento e o de acesso foi de 18,7\%, ou seja, esse percentual sugere que uma parte considerável de bolsistas já ouviram falar do Portal da Transparência, mas nunca o acessou.

O Portal da Transparência não fornece a informação da data de pagamento de forma antecipada quando a despesa com o pagamento da bolsa está na fase de liquidação. A percepção dos bolsistas em relação a esse aspecto foi objeto de um questionamento específico. A figura 5 mostra o resultado quanto à disponibilidade de se ter acesso à data de pagamento para auxiliar no controle financeiro dos alunos. 
Figura 5 Respostas dos bolsistas em relação aos dados de pagamento disponível no Portal da Transparência

Você acha que ter informação acessivel, no portal da transparência, sobre data do pagamento da bolsa, ajuda na sua rotina e controle financeiro?

387 responses

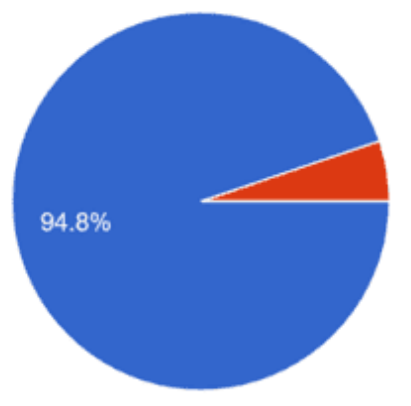

Fonte: Elaborado pelo próprio autor (2020)

Conforme mostrado na figura 5, a quase totalidade dos alunos responderam que ajudaria na sua rotina financeira se o Portal da Transparência disponibilizasse a data do pagamento da bolsa. Nas palavras de um dos respondentes: "Acredito que o Portal sim poderia ser uma ferramenta excelente pra nós, monitores, termos um maior controle financeiro".

Os alunos foram perguntados sobre o conhecimento de termos técnicos muito utilizados na plataforma, tais como empenho, liquidação e pagamento. Perguntados se conheciam esses termos, a maioria (79,7\% dos respondentes) informou que não, enquanto $20,3 \%$ afirmaram que conheciam. Esse resultado pode ser observado na figura 6 . 
Figura 6 Respostas dos bolsistas em relação aos termos técnicos utilizados como, empenho, liquidação e pagamento no Portal da Transparência

O portal da transparência possui informações sobre empenho, liquidação e pagamento. Você tem conhecimento de cada uma dessas fases?

389 responses

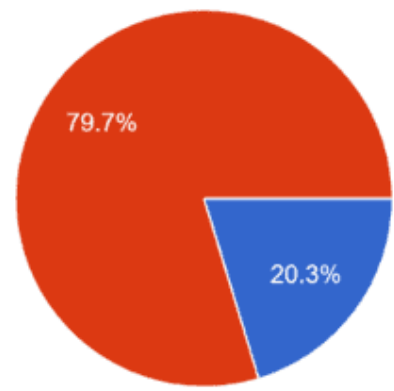

Fonte: Elaborado pelo próprio autor (2020)

Também foi solicitado que os bolsistas avaliassem o grau de dificuldade em analisar as informações contidas no Portal da Transparência considerando uma escala que varia de 0 (difícil compreensão) até 5 (fácil compreensão). A maioria dos respondentes $(33,2 \%)$ atribuiu grau 3 para o nível de dificuldade em analisar as informações contidas na plataforma. Esse resultado mostra que, apesar do portal possuir terminologias técnicas, parte dos alunos assinalaram um nível de dificuldade mediana para essa questão. Por sua vez, 39,3\% dos respondentes atribuíram graus de 0 a 2 sinalizando um elevado grau de dificuldade, enquanto 26,5\% marcaram graus 4 e 5 apontando uma fácil compreensão. A figura 7 mostra esses resultados. 
Figura 7 Avaliação dos bolsistas em relação aos termos técnicos utilizados no Portal da Transparência

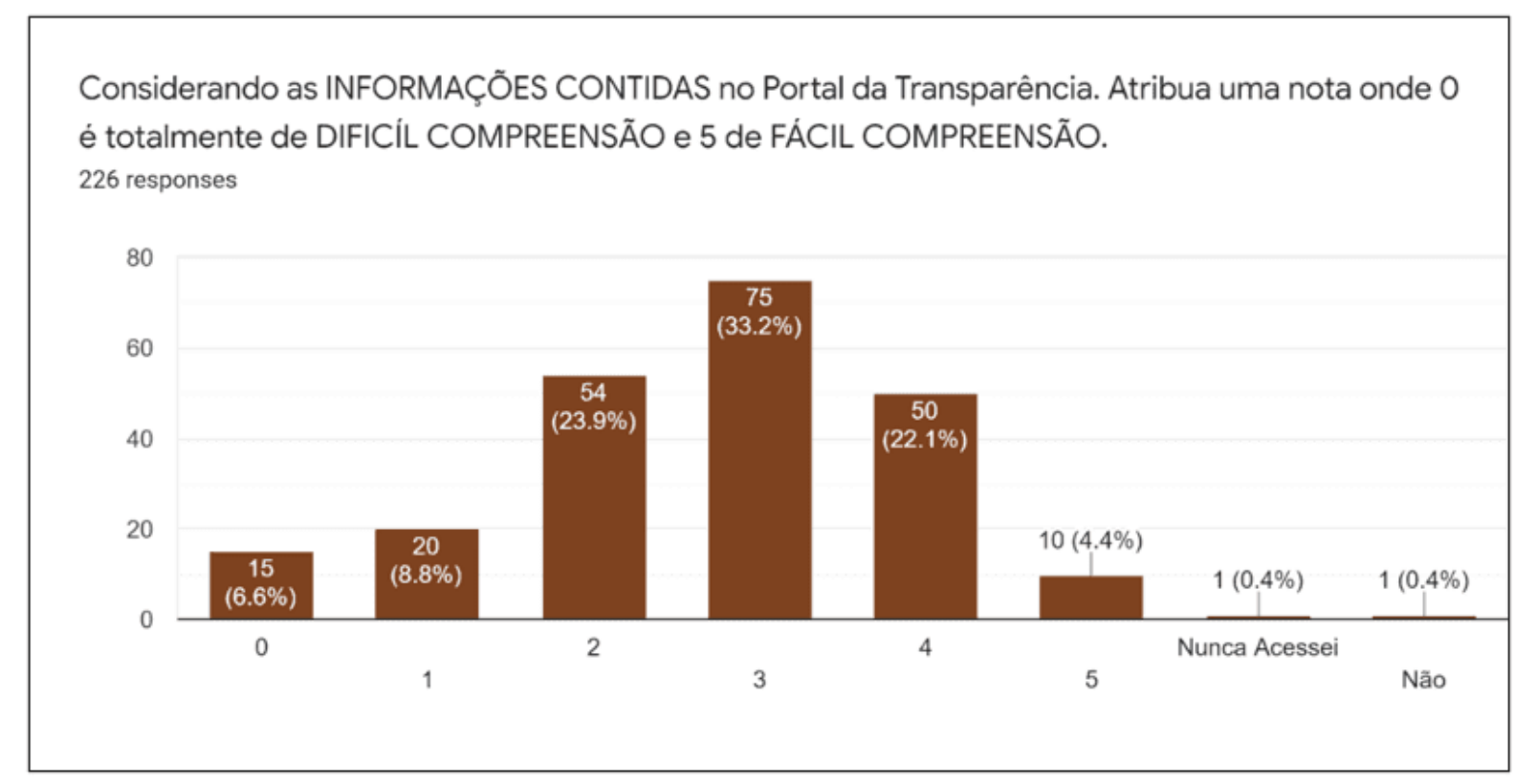

Fonte: Elaborado pelo próprio autor (2020).

O grau de dificuldade da pergunta anterior pode ser confrontado com os resultados da pergunta que consistia em avaliar a possibilidade de alterar os termos técnicos por uma linguagem mais simplificada. Considerando esse questionamento, 47,7\% concordaram que a mudança facilitaria a compreensão das informações contidas no referido portal, enquanto 17,5\% afirmam que a mudança seria irrelevante, ou seja, não necessária. Já $34,8 \%$ dos respondentes se consideraram incapaz de opinar. A figura 8 mostra, de forma geral, a visão dos bolsistas em relação aos termos técnicos utilizados no Portal da Transparência. 
Figura 8 Respostas dos bolsistas em relação aos termos técnicos utilizados no Portal da Transparência

Os termos utilizados no referido portal poderiam ser substituidos por uma linguagem mais informal?

388 responses
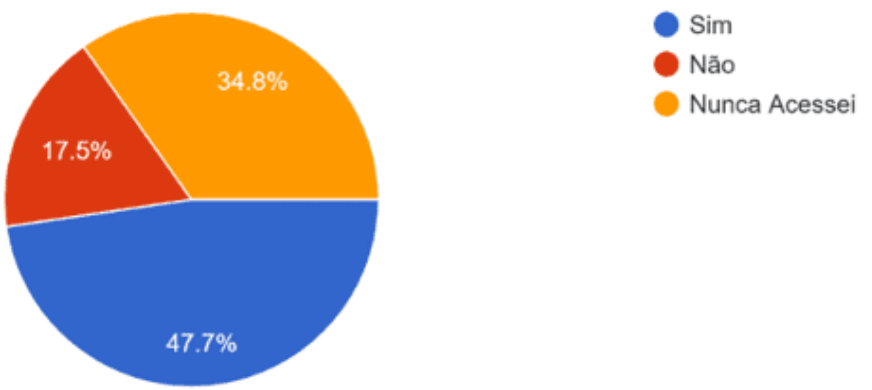

Fonte: Elaborado pelo próprio autor (2020).

Em relação à facilidade de navegação na plataforma, os bolsistas puderam avaliar o grau de dificuldade numa escala entra 0 e 5 , onde 0 significa que a dificuldade é grande e 5 que a navegação é fácil. De acordo com os dados coletados, os bolsistas consideram a navegação com um nível de dificuldade mediana. O percentual de respondentes que indicaram grau variando de 0 a 2 foi de $43,7 \%$, indicando maior grau de dificuldade de navegação. Já $20,9 \%$ sinalizaram graus 4 e 5, considerando maior facilidade de navegação no portal conforme ilustrado na figura 9. 
Figura 9 Avaliação dos bolsistas em relação a navegação no Portal da Transparência

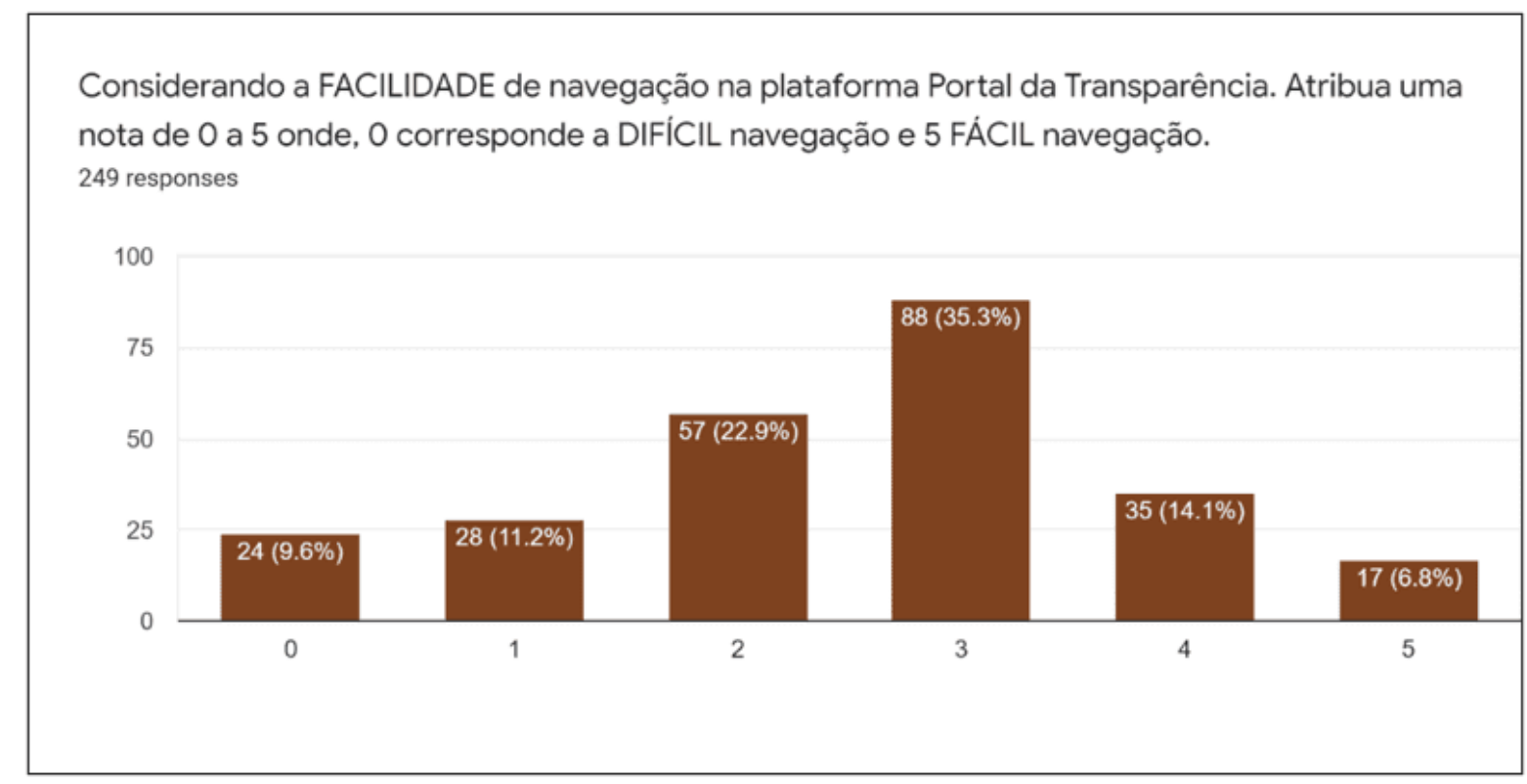

Fonte: Elaborado pelo próprio autor (2020)

Sobre a questão da navegação pela plataforma, os bolsistas ainda apresentaram os seguintes comentários:

Não consegui acompanhar muito bem minhas fases de recebimento da bolsa. Obrigado;

O portal da transparência traz MT eficiência em questões burocráticas;

Acho que o portal da transparência era mais fácil de ser utilizados antes da atualização (feita ano passado ou retrasado);

Tentei buscar informações referentes a minha pessoa no portal da transparência e não consegui acessar meus dados;

Acredito que o portal de transparências é claro, e deixa a disposição apenas as informações necessárias dos recebimentos dos bolsistas, sem expô-los demais;

Facilitar o entendimento e a navegação no portal da transparência;

Melhor entendimento do portal da transparência, divulgação da data de pagamento; 
Quando você bota o nome da pessoa aparecem mais de um item.

Visando avaliar o Portal da Transparência quanto a sua publicidade, ou seja, quanto é divulgado pelo poder público, os bolsistas puderam dar notas de acordo com a sua satisfação, conforme pode ser verificado na figura 10.

Figura 10 Avaliação dos bolsistas em relação a publicidade do Portal da Transparência

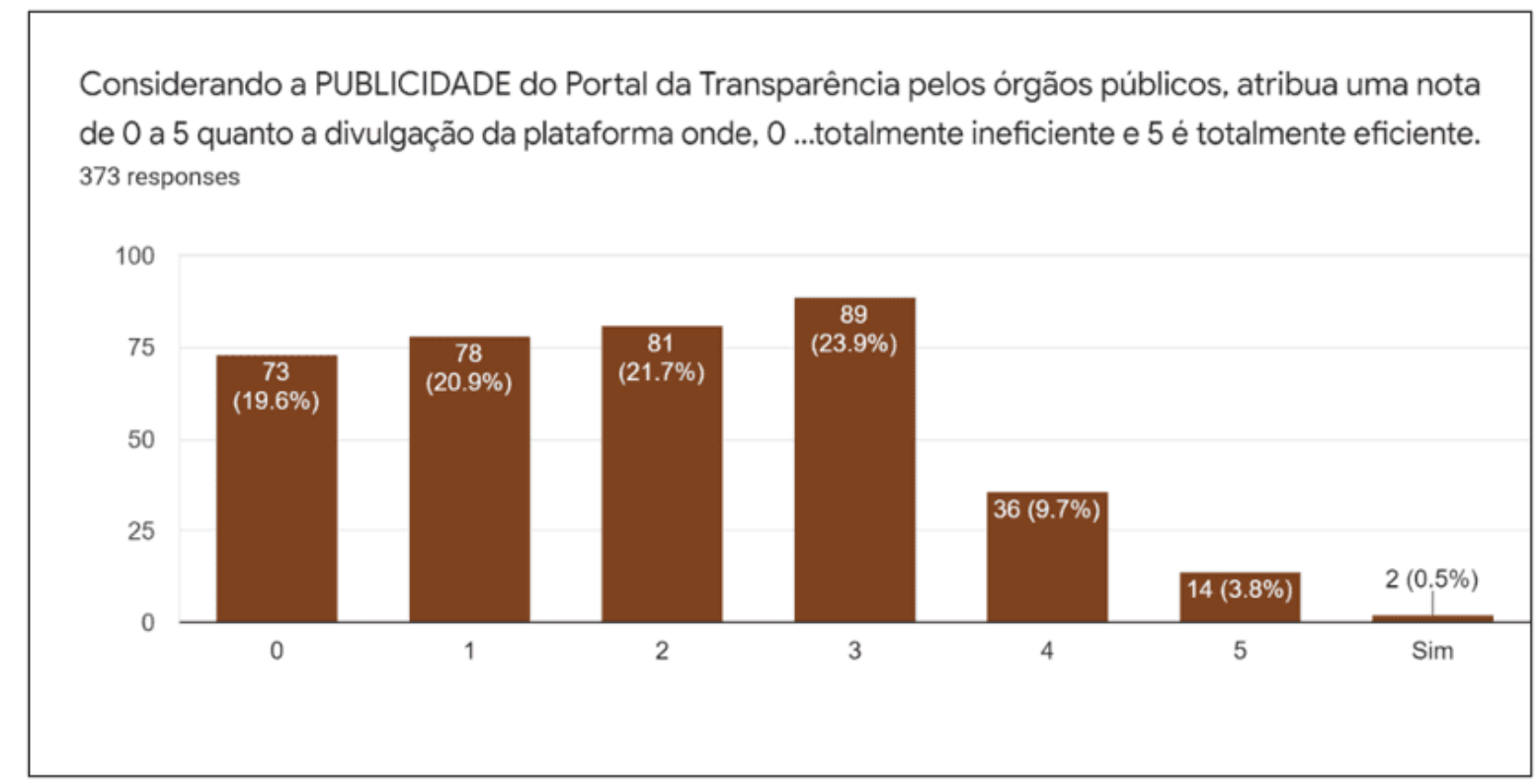

Fonte: Elaborado pelo próprio autor (2020).

Conforme pode ser observado, a maioria $(62,4 \%)$ dos respondentes considerou que a publicidade sobre o Portal da Transparência é ineficiente considerando o percentual de alunos que atribuiu graus de 0 a 2. Por sua vez, 23,9\% consideraram que existe uma divulgação do portal medianamente eficiente com grau 3 e apenas $13,5 \%$ consideraram eficiente, tendo atribuído graus 4 ou 5 . Esses resultados mostram que é preciso fazer uma maior divulgação do Portal da Transparência. 


\section{CONSIDERAÇÕES FINAIS}

Esse estudo buscou melhorar a interação dos bolsistas com o Portal da Transparência e fazer com que essa interação fomente a fiscalização e possa fazer com que o beneficiário tenha um melhor controle das suas finanças.

Apesar de boa parte dos bolsistas já ter ouvido falar no Portal da Transparência, pouco mais da metade já o tinha acessado. Os resultados também mostraram que os alunos acham que o Portal poderia conter informações sobre a data de pagamento das bolsas, o que permitiria um maior planejamento e controle financeiro por parte dos alunos.

De acordo com as respostas do questionário, os alunos avaliam que o Portal poderia conter uma linguagem com termos de mais fácil compreensão, bem como, possuir maior facilidade de navegação. Acrescenta-se que os alunos também consideram que existe pouca divulgação dessa ferramenta de acesso a informações públicas.

Assim sendo, para que o Portal da Transparência seja amplamente utilizado, seria importante uma maior visibilidade e publicidade da ferramenta, estimulando sua utilização. Também seria desejável a elaboração de uma legenda para uma melhor compreensão dos termos técnicos utilizados na plataforma, bem como, um manual de buscas de informações individualizadas.

\section{REFERÊNCIAS}

ANDRADE, E. G. R. DE et al. Contribuição da monitoria acadêmica para o processo ensino-aprendizagem na graduação em enfermagem. Revista Brasileira de Enfermagem, v. 71, n. suppl 4, p. 1596-1603, 2018.

BRASIL. PORTAL DA TRANSPARÊNCIA. . O que é e como funciona. Disponível em: http://www.portaltransparencia.gov.br/sobre/o-que-e-e-como-funciona. Acesso em: 24 fev. 2019. 
BRASIL. PORTAL DA TRANSPARÊNCIA. . O que você encontra no Portal. Disponível em: http://www.portaltransparencia.gov.br/sobre/o-que-voce-encontra-noportal. Acesso em: 24 fev. 2019.

BRASIL. Lei Complementar $n^{\circ}$ 131, de 27 de maio de 2009. Determina a disponibilização, em tempo real, de informações pormenorizadas sobre a execução orçamentária e financeira da União, dos Estados, do Distrito Federal e dos Municípios. Diário Oficial da União, Brasília, 28 maio 2009. Disponível em:<http://www.planalto.gov.br/ccivil_03/leis/lcp/lcp131.htm>Acesso em: 20 jul. 2019.

BRASIL. Lei $n^{\circ} 12.527$, de 18 de novembro de 2011. Regula o acesso a informações. Dispõe sobre os procedimentos a serem observados pela União, Estados, Distrito Federal e Municípios, com o fim de garantir o acesso a informações. Diário Oficial da União, Brasília, 18 nov. 2011b. Disponível em: <http://www.planalto.gov.br/ccivil_03/_ato2011-2014/2011/lei/12527.htm>. Acesso em: 20 mar. 2019.

BRASIL. Lei Complementar $n^{\circ} 131$, de 27 de maio de 2009. Determina a disponibilização, em tempo real, de informações pormenorizadas sobre a execução orçamentária e financeira da União, dos Estados, do Distrito Federal e dos Municípios. Diário Oficial da União, Brasília, 28 maio 2009. Disponível em:<http://www.planalto.gov.br/ccivil_03/leis/lcp/lcp131.htm>Acesso em: 20 jul. 2019.

BRASIL. INSTITUTO FEDERAL DO PIAU - IFPI. Assistência Estudantil. Disponível em: https://www.ifpi.edu.br/area-do-estudante/assistencia-estudantil. Acesso em: 23 mar. 2020.

BRUSCA, I.; MARTíNEZ, J. C. Adopting International Public Sector Accounting Standards: a challenge for modernizing and harmonizing public sector accounting. International Review of Administrative Sciences, v. 82, n. 4, p. 724-744, 2016. 
CALDAS, O. V.; COSTA, C. M.; PAGLIARUSSI, M. S. Corrupção e composição dos gastos governamentais: Evidências a partir do Programa de Fiscalização por Sorteios Públicos da Controladoria-Geral da União. Revista de Administracao Publica, v. 50, n. 2, p. 237-264, 2016.

Flick, U. (2006) An introduction to Qualitive Research, 3rd edn. London: Sage.

FUMEC, U. et al. QUALIDADE DE SOFTWARE PERCEBIDA PELOS USUÁRIOS DO SISTEMA SIAFI: um estudo de caso em um Instituto Federal em Minas Gerais. 2011.

GAMA, J. R.; RODRIGUES, G. M. Transparência e acesso à informação: um estudo da demanda por informações contábeis nas universidades federais brasileiras. Transinformacao, v. 28, n. 1, p. 47-57, 2016.

GANT, J. P. Electronic Government for Developing Countries. International Telecommunications Union, n. August, p. 59, 2008.

GRIMMELIKHUIJSEN, S. et al. The effect of transparency on trust in government: A cross-national comparative experiment. Public Administration Review, v. 73, n. 4, p. 575-586, 2013.

INGRAMS, A. (2017). Connective action and the echo chamber of ideology: Testing a model of social media use and attitudes toward the role of government. Journal of Information Technology \& Politics, 14(1), 1-15.

INTEGRADA, U. R. et al. Acesso À Informação E Transparência Na Administração Pública. Revista de Administração, v. 11, n. 20, p. 49-69, 2014.

JENSEN, P. R.; MEISENBACH, R. J. Alternative Organizing and (In)Visibility: Managing Tensions of Transparency and Autonomy in a Nonprofit Organization. Management Communication Quarterly, v. 29, n. 4, p. 564-589, 2015. 
JOHNSTON, M. Limits and ironies of transparency: Controlling corruption in American elections. Election Law Journal: Rules, Politics, and Policy, v. 18, n. 3, p. 282-296, 2019.

LANDAHL, J. Learning to listen and look: the shift from the monitorial system of education to teacher-led lessons. Senses and Society, v. 14, n. 2, p. 194-206, 2019.

MENDES, M. S. Da inclusão à evasão escolar: o papel da motivação no ensino médio. Estudos de Psicologia (Campinas), v. 30, n. 2, p. 261-265, 2013.

MICHENER, G.; CONTRERAS, E.; NISKIER, I. From opacity to transparency ? Evaluating access to information in Brazil five years later. v. 52, n. 4, p. 610-629, 2018.

PAPA, TEREZA FERNANDA MARTUSCELLO. Vantagens e desvantagens do processo eletrônico. Revista Jus Navigandi, ISSN 1518-4862, Teresina, ano 19, n. 3961, 6 maio 2014. Disponível em: https://jus.com.br/artigos/28122. Acesso em: 24 ago. 2020.

PETHIG, F.; KROENUNG, J. Specialized Information Systems for the Digitally Disadvantaged. v. 20, p. 1412-1446, 2019.

RAMÍREZ, Y.; TEJADA, Á. Digital transparency and public accountability in Spanish universities in online media. Journal of Intellectual Capital, v. 20, n. 5, p. 701-732, 2019.

RIBEIRO, C. V. DOS S.; MANCEBO, D. O servidor público no mundo do trabalho do século XXI. Psicologia: Ciência e Profissão, v. 33, n. 1, p. 192-207, 2013.

RICARDO, P.; ABDALA, Z. A Transparência como Espetáculo: uma análise dos portais de transparência de estados brasileiros. Administração Pública e Gestão Social, v. 8, n. 3, p. 147-158, 2016. 
SANTOS, L. C.; DENNER, C. Information technology A study on the impact of non-operational mechanisms on the effectiveness of public information technology governance. Revista de Administração, v. 52, n. 3, p. 256-267, 2017.

SHAMBAUGH, G. E.; SHEN, E. B. A clear advantage: The benefits of transparency to crisis recovery. European Journal of Political Economy, v. 55, n. February 2017, p. 391-416, 2018.

SHUMATE, M.; O'CONNOR, A. The symbiotic sustainability model: Conceptualizing NGO-corporate alliance communication. Journal of Communication, v. 60, n. 3, p. 577-609, 2010.

UNIVERSIA. Bolsa faculdade: todos os tipos de auxílio financeiro no Brasil e no exterior. 2020.

Disponível em: https://www.universia.net/br/actualidad/actualidad.orientacion-academica.os-tiposde-auxilio-no-brasil-e-no-exterior.html. Acesso em: 04 dez. 2020.

VALLE-CRUZ, D. Public value of e-government services through emerging technologies. International Journal of Public Sector Management, v. 32, n. 5, p. 473488, 2019.

WATAKABE, T. A evasão escolar dos alunos cotistas sociais na educação profissional. Revista Espaço Acadêmico, v. 15, n. 170, p. 87-98, 2015.

Enviado: Janeiro, 2021.

Aprovado: Janeiro, 2021. 